University of Nebraska - Lincoln

DigitalCommons@University of Nebraska - Lincoln

Negative correlation between porosity and hydraulic conductivity in sand-and-gravel aquifers at Cape Cod, Massachusetts, USA

Roger H. Morin

Denver Federal Center, roger.morin49@gmail.com

Follow this and additional works at: https://digitalcommons.unl.edu/usgsstaffpub

Part of the Earth Sciences Commons

Morin, Roger H., "Negative correlation between porosity and hydraulic conductivity in sand-and-gravel aquifers at Cape Cod, Massachusetts, USA" (2005). USGS Staff -- Published Research. 358.

https://digitalcommons.unl.edu/usgsstaffpub/358

This Article is brought to you for free and open access by the US Geological Survey at DigitalCommons@University of Nebraska - Lincoln. It has been accepted for inclusion in USGS Staff -- Published Research by an authorized administrator of DigitalCommons@University of Nebraska - Lincoln. 


\title{
Negative correlation between porosity and hydraulic conductivity in sand-and-gravel aquifers at Cape Cod, Massachusetts, USA
}

\author{
Roger H. Morin* \\ United States Geological Survey, Denver, CO 80225, USA
}

Received 3 March 2004; revised 8 April 2005; accepted 14 April 2005

\begin{abstract}
Although it may be intuitive to think of the hydraulic conductivity $K$ of unconsolidated, coarse-grained sediments as increasing monotonically with increasing porosity $\Phi$, studies have documented a negative correlation between these two parameters under certain grain-size distributions and packing arrangements. This is confirmed at two sites on Cape Cod, Massachusetts, USA, where groundwater investigations were conducted in sand-and-gravel aquifers specifically to examine the interdependency of several aquifer properties using measurements from four geophysical well logs. Along with $K$ and $\Phi$, the electrical resistivity $R_{0}$ and the natural gamma activity $\gamma$ of saturated deposits were determined as functions of depth. Qualitative examination of results from the first site implies a negative correlation between $K$ and $\Phi$ that is substantiated by a rigorous multivariate analysis of log data collected from the second site. A principal components analysis describes an overdetermined system of inversion equations, with approximately $92 \%$ of the cumulative proportion of the total variance being accounted for by only three of the four eigenvectors. A subsequent $R$-mode factor analysis projects directional trends among the four variables $\left(K, \Phi, R_{0}\right.$ and $\left.\gamma\right)$, and a negative correlation between $K$ and $\Phi$ emerges as the primary result.
\end{abstract}

(C) 2005 Elsevier B.V. All rights reserved.

Keywords: Geophysical logs; Porosity; Hydraulic conductivity; Granular deposits

\section{Introduction}

The hydraulic conductivity of granular deposits is generally considered as being dependent upon porosity and sorting. As porosity increases or decreases, the hydraulic conductivity of coarsegrained sediments is thought to monotonically follow the same trend (e.g. Nelson, 1994). Other factors such as grain size and shape, tortuosity, packing arrangement, and pore shape also affect the hydraulic conductivity of these materials. Vukovic and Soro (1992) present an extensive compilation of empirical formulas that consider both porosity and sorting in the computation of hydraulic conductivity. These investigators recommend using the Zunker formula for fine and medium grain-size sand, and the Zamarin formula for large grain sands.

The Zunker empirical formula takes the form

$$
K=\frac{g}{v} \beta_{\mathrm{Z}}\left[\frac{\Phi}{1-\Phi}\right] d_{\mathrm{e}}^{2}
$$

* Tel.: +1 303236 5915; fax: + 13032365968 .

E-mail address: rhmorin@usgs.gov

0022-1694/\$ - see front matter (C) 2005 Elsevier B.V. All rights reserved. doi:10.1016/j.jhydrol.2005.04.013 
and the Zamarin formula is represented by the relation

$K=\frac{g}{v} \beta_{\mathrm{ZN}}\left[\frac{\Phi^{3}}{(1-\Phi)^{2}}\right] d_{\mathrm{e}}^{2}$

In Eqs. (1) and (2), $K$, hydraulic conductivity $(\mathrm{L} / \mathrm{T}) ; g$, gravitational constant $\left(\mathrm{L} / \mathrm{T}^{2}\right) ; \nu$, kinematic viscosity $\left(\mathrm{L}^{2} / \mathrm{T}\right) ; \Phi$, total porosity (dimensionless); $\beta_{\mathrm{Z}}$, empirical coefficient based on sorting and grain shape (dimensionless); $\beta_{\mathrm{ZN}}$, empirical coefficient based on porosity (dimensionless); and $d_{\mathrm{e}}$, effective grain diameter (L). Other empirical investigations have shown that grain size is the fundamental independent parameter that controls hydraulic conductivity in unconsolidated sediments (e.g. Hazen, 1911; Pryor, 1973). Shepherd (1989) summarizes this work with the expression

$P=C d^{2}$

where $P$ is the permeability $\left(\mathrm{L}^{2}\right), d$ is a representative grain size (L), and $C$ is a dimensionless proportionality constant. This constant may encompass a variety of factors, including path tortuosity and particle shape.

Experimental studies of grain packing (Fraser, 1935) and grain-packing models based on mixed grain-size populations (Marion et al., 1992; Kolterman and Gorelick, 1995) have demonstrated that the porosity of a granular material varies with the volume fraction of fines (Fig. 1) and that it reaches a minimum value, $\Phi_{\min }$, when the volume of fine-grained particles equals the porosity of the coarse-grained particles.

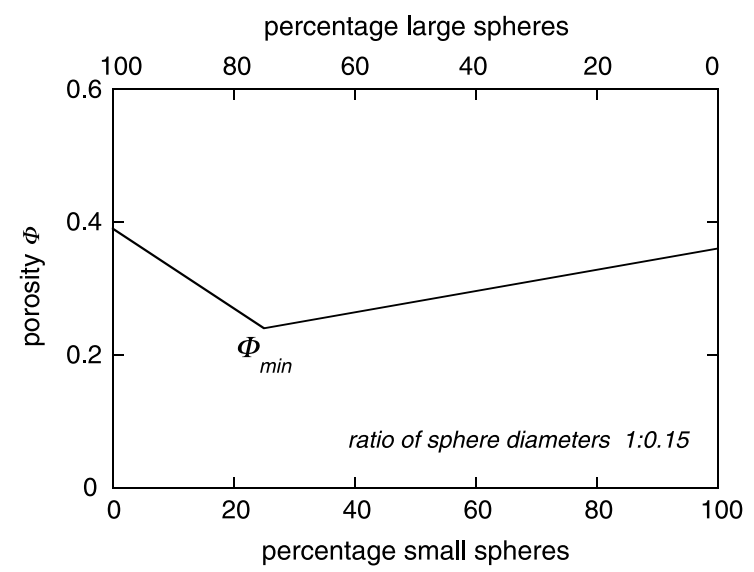

Fig. 1. Illustration of packing effect on porosity (modified from Fraser, 1935).
At this stage, the fines fill much of the void space produced by the packed coarse grains. As the fines content continues to increase to the right of the inflection point, $\Phi_{\min }$ (Fig. 1), the larger grains become suspended in the accumulating mix of fines. At this subsequent stage, the representative grain diameter, $d$, decreases but the porosity increases. Moreover, this decrease in $d$ occurs at a faster rate than does the corresponding increase in $\Phi$. Consequently, if the hydraulic conductivity of a granular material is based predominantly on grain size (Eq. (3)), $K$ may decrease with increasing porosity under changes in grain-packing schemes. Although the relation presented in Fig. 1 was developed for a mixture of two distinct grain sizes, it has been recognized in real field samples (Graton and Fraser, 1935; Beard and Weyl, 1973; Clarke, 1979).

In the work reported herein, this negative correlation between porosity and hydraulic conductivity in granular deposits is examined through the multivariate analysis of geophysical log data. Logs were obtained in shallow wells at two sites on Cape Cod, Massachusetts, to help characterize the local sand-and-gravel aquifers prevalent throughout the

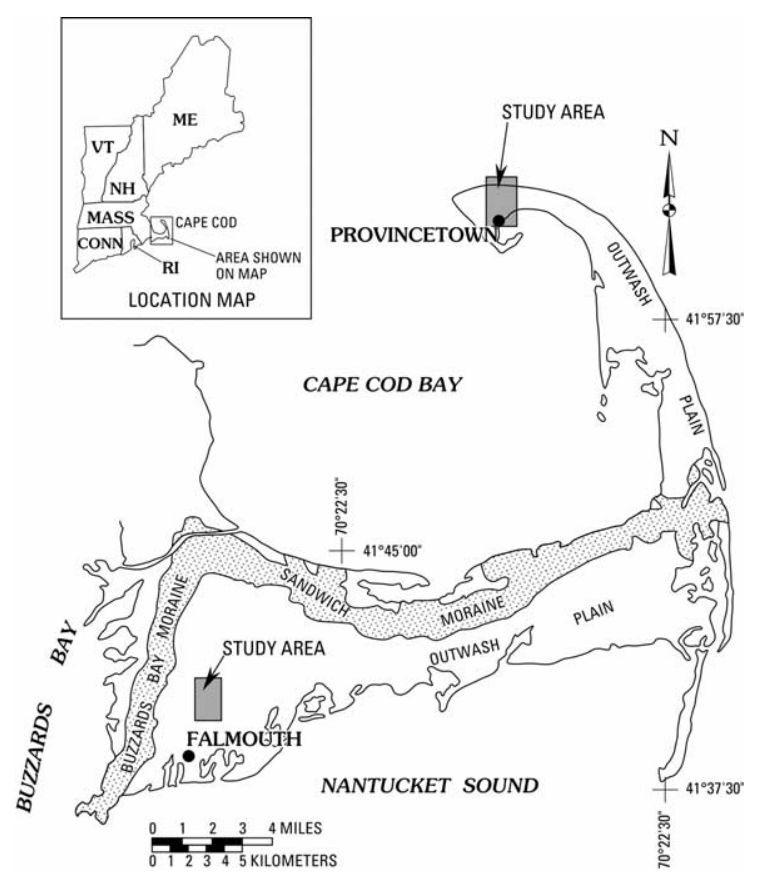

Fig. 2. Location of two study sites on Cape Cod, Massachusetts. 
peninsula (LeBlanc et al., 1986; Oldale, 1992; Uchupi et al., 1996). At the first site in Provincetown (Fig. 2), these downhole measurements indicated that groundwater flow was confined to one particular hydrostratigraphic unit having a higher hydraulic conductivity but a lower porosity than adjacent deposits. At a second site in Falmouth, geophysical logs were obtained that provided continuous vertical profiles of several physical parameters. Here, test conditions were more favorable for undertaking a detailed statistical study that built upon the observations at Provincetown to investigate the interdependence of hydraulic conductivity and porosity. Results from both field sites on Cape Cod depict a negative correlation between these two properties that may have implications in the modeling of physical processes associated with groundwater flow and transport through granular deposits.

\section{Provincetown study site}

\subsection{Site description and field measurements}

The first study area is located in Provincetown, Massachusetts, at the northern tip of Cape Cod (Fig. 2). It is situated within and adjacent to the Cape Cod National Seashore on a glacial-outwash plain. The Provincetown area was formed by northerly coastal drift and deposition of ocean-reworked glacial sands over $60 \mathrm{~m}$ thick since the close of the Wisconsin Glaciation some 12,000 years ago (Strahler, 1972). These deposits overlie ancient Eocene sediments (Zeigler et al., 1965); bedrock is at a depth of about $150 \mathrm{~m}$ in the central part of the region (Strahler, 1972).

A series of five monitoring wells is located between Provincetown Harbor and the Provincetown landfill about $1000 \mathrm{~m}$ to the northwest. The wells are roughly $30 \mathrm{~m}$ deep, are constructed with $5.1-\mathrm{cm}$ diameter PVC casing, and penetrate unconsolidated sand-and-gravel deposits. Geophysical logs were obtained in these wells in an effort to locate a contaminant plume emanating from the landfill and migrating toward the harbor. Morin and Urish (1995) present a detailed analysis of the logs and report on the hydrogeologic characteristics of the aquifer. For the purposes of this study, attention is limited to the well closest downgradient from the landfill and to three specific downhole measurements: the natural gamma $\log$, the neutron porosity $\log$, and the electromagnetic induction log (Fig. 3).

The natural gamma log is a measure of the natural gamma radiation being emitted by the surrounding sediments. Clays tend to accumulate radioisotopes through adsorption and ion-exchange processes, and zones of high gamma activity detected by a logging probe are typically interpreted as being clay rich. However, in the granular deposits of Cape Cod where clays are virtually absent (Barber et al., 1992), intervals exhibiting high gamma activity more often correspond to coarse and immature glauconitic sands.

The neutron probe used in this study was a singledetector epithermal tool that yields an estimate of formation porosity. This tool has been calibrated in specially designed test pits and the response of the neutron detector, in counts per second, can be accurately converted to quantitative values of total porosity provided the formation is saturated. However, because the wells at this site were constructed with a hollow-stem auger, inaccuracies in the estimation of in situ saturated porosity may result from physical disturbances to the aquifer caused by material collapsing around the annulus between the exterior augered hole and the PVC casing inserted in the hole (Morin et al., 1988a). Thus, it should be recognized that there could be slight errors in the porosity estimates derived from the neutron log in this particular application.

Finally, the electromagnetic induction tool, which operates at a frequency of $40 \mathrm{kHz}$, provides a measure of the electrical conductivity (or resistivity, its inverse) of the surrounding saturated sediments and is particularly effective in identifying freshwaterseawater interfaces. However, where pore-water conductance is relatively uniform, resistivity in clastic aquifers will commonly vary proportionally with grain size and inversely with porosity. Lower resistivity corresponds to smaller grain size because the greater surface area associated with fine particles promotes the transmission of electric current (e.g. Biella et al., 1983; Kwader, 1985). Since the primary conducting medium is the fluid, lower resistivity can also be indicative of higher porosity. Hearst et al. (2000) present additional information on these logging tools and their principles of operation. 


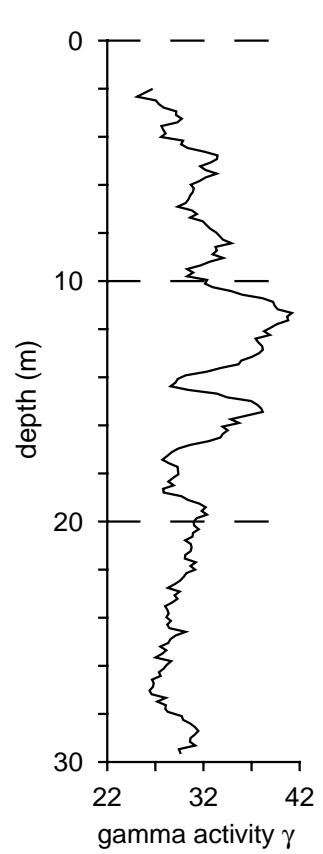

(cps)

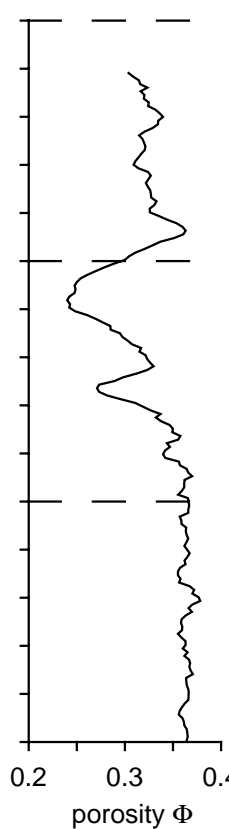

porosity $\Phi$

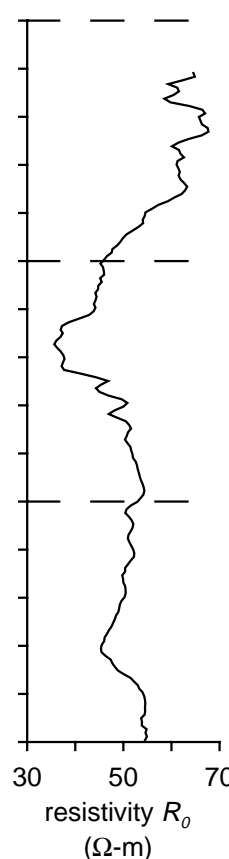

$(\Omega-\mathrm{m})$

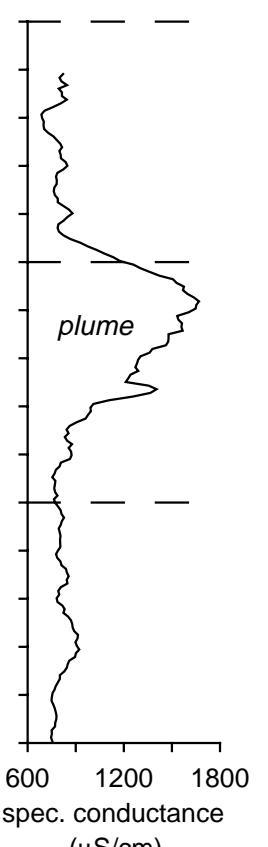

$(\mu \mathrm{S} / \mathrm{cm})$

Fig. 3. Composite of logs obtained from one monitoring well in Provincetown nearest the landfill. The specific conductance was calculated from the porosity and resistivity logs using Archie's law (Archie, 1942).

The log composite presented in Fig. 3 displays a low-porosity zone from about 9 to $14 \mathrm{~m}$ depth. This interval is coincident with higher gamma activity and with lower resistivity. Assuming that the pore-fluid resistivity remains uniform throughout the aquifer, the formation resistivity is expected to increase as porosity decreases and also increase as gamma activity increases (high gamma counts indicative of coarse grains). That the resistivity decreases across this 5-m thick interval indicates that fluid resistivity is low enough to counteract the effects of porosity and grain size. The true values of pore-fluid resistivity with respect to depth can be computed by combining the porosity and resistivity logs, and applying Archie's law (Archie, 1942)

$R_{\mathrm{W}}=\frac{\Phi^{m} R_{0}}{a}$

where $R_{\mathrm{W}}$, pore-water resistivity $(\Omega \mathrm{m}) ; R_{0}$, saturated formation resistivity $(\Omega \mathrm{m}) ; m$, cementation factor, and $a$, pore-geometry coefficient. The value of $a$ is assumed to be 1.0 for most granular systems and that of $m$ approximately equal to 1.4 for cohesionless sands and gravels (Kwader, 1986). Substituting these values into Eq. (4) and inserting the values for $R_{0}$ and $\Phi$ determined directly from the $\log$ y yields a continuous vertical profile of pore-water resistivity $R_{\mathrm{W}}$ for this well that can then be converted to specific conductance, as shown in the last panel of Fig. 3.

\subsection{Results and discussion}

The $\log$ composite of Fig. 3 shows that the presence of a contaminant plume is reflected in the specific conductance $\log$ and that the plume is confined within about a 5-m thick unit from 9 to $14 \mathrm{~m}$ depth. That it flows preferentially through this interval implies that this unit has a higher hydraulic conductivity than adjacent sediments. The complementary porosity and natural gamma logs delineate a low-porosity and coarse-grained interval, respectively, that corresponds to this depth. Thus, the logs in combination define a dominant hydrostratigraphic unit that is characterized by higher hydraulic conductivity and larger representative grain size, but lower porosity. 
This interpretation of the field logs provides implicit evidence of a negative correlation between porosity and hydraulic conductivity at this site. Complementary laboratory analyses of split-spoon samples recovered from this well at multiple depths verify that deposits located within the plume path have relatively larger grain sizes and contain fewer fines (Urish et al., 1993). However, the variation in hydraulic conductivity with depth was not measured directly and porosity estimates derived from the neutron $\log$ are somewhat suspect due to possible aquifer disturbance resulting from the well-installation technique (Morin et al., 1988a). Nevertheless, the information provides the conceptual framework from which to design a more rigorous study where field conditions are more amenable to obtaining quality measurements in situ.

\section{Falmouth study site}

\subsection{Site description and field measurements}

The study area is located near the town of Falmouth on an extensive glacial outwash plain that forms the western part of Cape Cod (Fig. 2). Sediments here were deposited by braided streams emanating from the receding ice sheets of the Pleistocene Epoch (Oldale, 1981). Field work was conducted at the US Geological Survey's Toxic Substances Hydrology Research Site where the aquifer is composed of unconsolidated granular materials that overlie crystalline bedrock at a depth of roughly $90 \mathrm{~m}$. Within this surficial section, medium- to coarse-grained deposits overlie finergrained sediments at a depth of about $50 \mathrm{~m}$ (LeBlanc, 1984; LeBlanc et al., 1986).

Two wells were selected in which to perform a detailed investigation designed to identify possible correlations among several physical parameters measured in situ using geophysical logs. These wells were chosen because: (1) they had been constructed by driving and washing flush-jointed steel pipe into which was inserted 5.1-cm diameter PVC casing, and (2) because the wells were fully screened. The drive-and-wash drilling method of casing installation has been shown to minimize disturbance to the surrounding aquifer fabric (Morin et al., 1988a), thereby improving the accuracy of the neutron porosity log; the fully-screened construction permits the vertical distribution of hydraulic conductivity to be determined at a high spatial resolution using the flowmeter-pumping technique (Hufschmied, 1986; Morin et al., 1988b; Rehfeldt et al., 1989). These two improvements to fieldtesting conditions, as compared to the previous Provincetown analysis, bring more confidence to the estimates of formation porosity and add quantitative values of $K$.

Unlike the contamination conditions recognized in the Provincetown study, the treated-wastewater plume at this site (LeBlanc, 1984) is too dilute to be detected with our present logging tools. Consequently, preferential flow pathways attributed to high hydraulic conductivities could not be deduced from specific conductance profiles. However, the long screens allowed the horizontal hydraulic conductivity to be measured directly at different depths. In addition to hydraulic conductivity and porosity, natural gamma activity and electrical resistivity were also measured in a manner identical to the previous study and with the same tools. For the sake of brevity, a log composite from only one of two wells is shown in Fig. 4, though results from both wells are similar. The plot of hydraulic conductivity was developed from measurements of vertical flow taken at $15.2-\mathrm{cm}$ depth intervals during pumping at a constant rate of 7.7 L/min. The small gaps in this profile represent blank casing collars where no flow could enter the pumped well.

\subsection{Analysis of multivariate log data}

Multivariate analyses of geophysical logging data have been previously used to identify fine-scale structural trends in aquifers (e.g. Kassenaar, 1991; Barrash and Morin, 1997). The data set represented by the four profiles in Fig. 4 provides a similar opportunity to conduct a systematic statistical analysis designed to identify and evaluate interrelationships among independent variables measured in situ.

From implementation of the flowmeter-pumping test, values of hydraulic conductivity were determined across consecutive $15.2-\mathrm{cm}$ depth intervals penetrating the sand-and-gravel aquifer. However, the other 


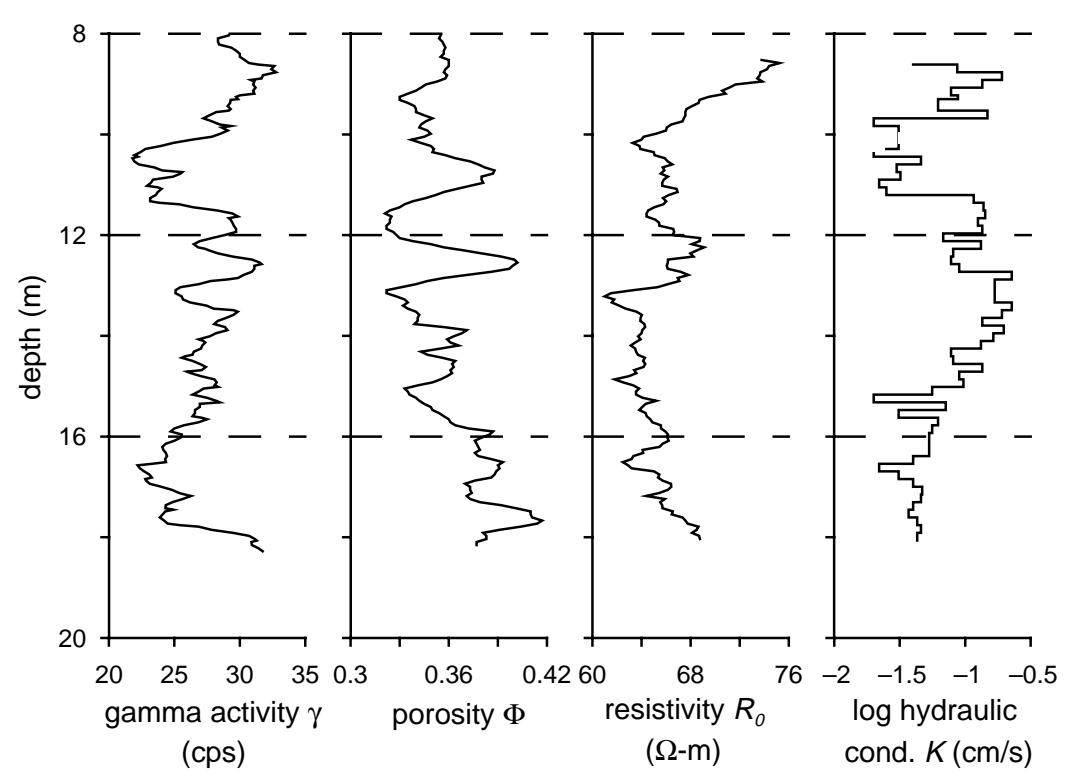

Fig. 4. Composite of logs obtained from well at the USGS Toxic Substances Hydrology Research Site near Falmouth, Massachusetts.

geophysical logs shown in Fig. 4 were routinely collected at $3-\mathrm{cm}$ intervals. In order to insure that all measurements obtained at a common depth represented the same sampling volume, the latter data were averaged over the same $15.2-\mathrm{cm}$ intervals coincident to the hydraulic conductivity values. Consequently, each depth interval has associated with it a unique value of hydraulic conductivity $(K)$, porosity $(\Phi)$, gamma activity $(\gamma)$, and electrical resistivity $\left(R_{0}\right)$. Because the hydraulic conductivity data vary over an order of magnitude, a logarithmic transform is applied to make their distribution more normal. The final data set to be analyzed statistically is comprised of these four independent variables arranged into a $57 \times 4$ matrix (Table 1 ). The four columns represent the four measurements derived from geophysical $\operatorname{logs}\left(\Phi, R_{0}, \gamma, \log K\right)$ and the 57 rows depict sequential depths within the aquifer. A symmetric matrix of crossplots constructed from all combinations of variables is presented in Fig. 5.

As a starting point in this analysis, principal components are used to develop insight into the structure of the data matrix by recombining the total variance in the system unequally among the variables (Davis, 1986). Principal components are the eigenvectors of the variance-covariance or correlation matrix, and their application standardizes variables having different units. This exercise is described by the following matrix manipulation

$X^{\mathrm{T}} X=Z D^{2} Z^{\mathrm{T}}$

where $X$ is the standardized $[n \times p]$ data matrix ( $n$, number of observations; $p$, number of variables), $Z$ is an orthonormal matrix $[p \times p]$, and $D$ is a diagonal matrix $[p \times p]$. The diagonal elements of $D^{2}$ are eigenvalues of $X^{\mathrm{T}} X$ and the columns of $Z$ are its eigenvectors. These eigenvectors define the principal components. It should be noted that a review of basic

Table 1

Data matrix $(57 \times 4)$ of $\log$-derived variables

\begin{tabular}{lllll}
\hline $\begin{array}{l}\text { Samples/ } \\
\text { depth } \\
\text { intervals }\end{array}$ & $\begin{array}{l}\text { Porosity, } \\
\Phi\end{array}$ & $\begin{array}{l}\text { Resis- } \\
\text { tivity, } R_{0} \\
(\Omega \mathrm{m})\end{array}$ & $\begin{array}{l}\text { Gamma } \\
\text { activity, } \gamma \\
(\mathrm{cps})\end{array}$ & $\begin{array}{l}\text { Log } \\
\text { hydraulic } \\
\text { cond., } K \\
(\mathrm{~cm} / \mathrm{s})\end{array}$ \\
\hline 1 & 0.360 & 74.82 & 31.39 & -1.397 \\
2 & 0.357 & 73.69 & 31.94 & -1.061 \\
3 & 0.343 & 71.15 & 30.83 & -0.719 \\
- & - & - & - & - \\
- & - & - & - & - \\
- & - & - & - & - \\
57 & 0.381 & 68.66 & 31.30 & -1.366 \\
\hline
\end{tabular}



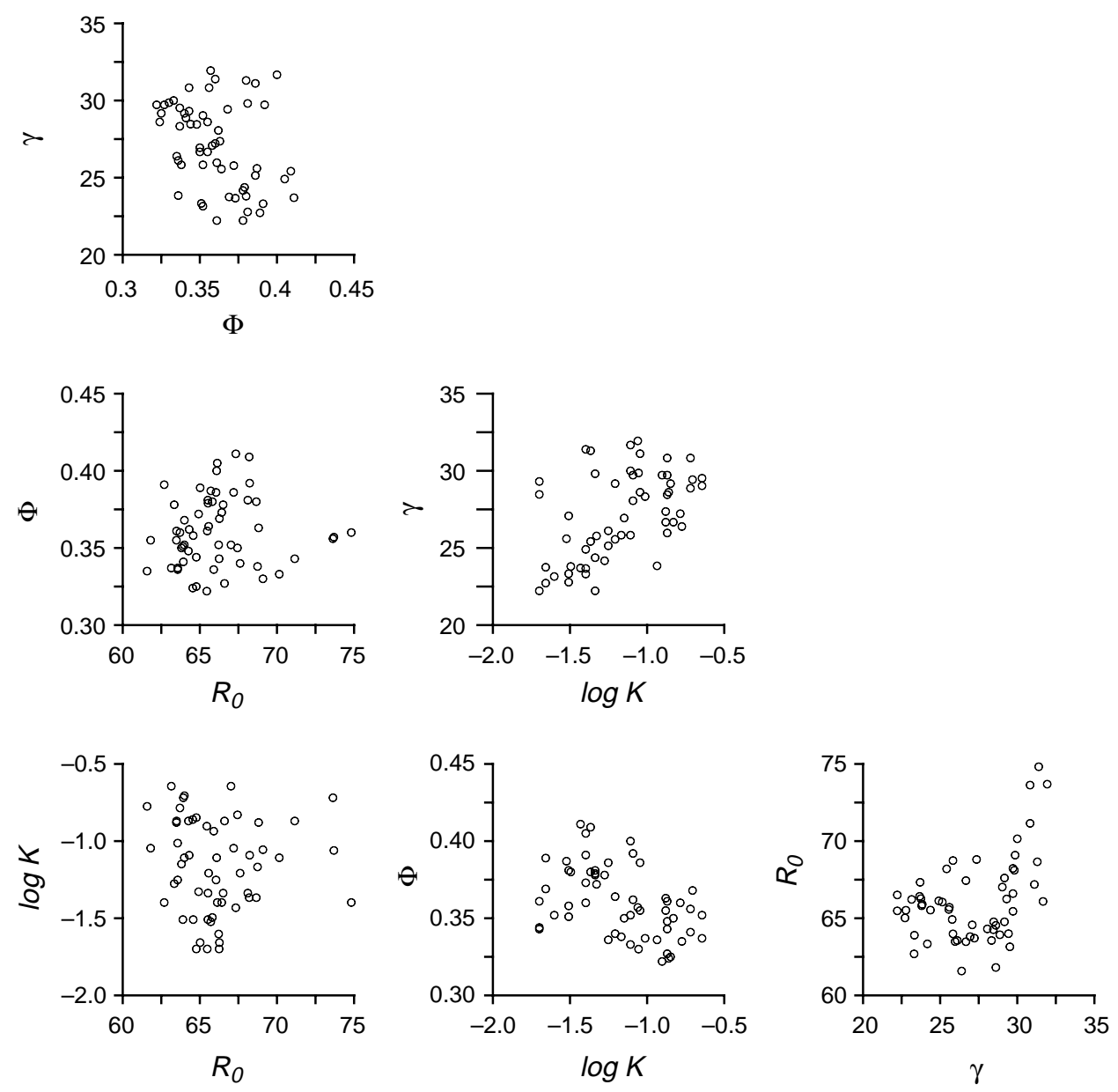

Fig. 5. Symmetric matrix of crossplots between the four variables $K$ (hydraulic conductivity), $R_{0}$ (electrical resistivity), $\Phi$ (porosity), and $\gamma$ (natural gamma activity).

statistical principles and a detailed description of each processing step undertaken as part of this study are beyond the scope and context of this paper.

The variables are weighted equally, and the standard deviations of the four principal components are listed in Table 2; the resulting coefficients of the eigenvectors, or loadings, associated with the individual variables are displayed in Fig. 6. Moreover, as can be seen in Table 2, approximately $92 \%$ of the cumulative proportion of the total variance is accounted for by the first three principal components. Consequently, an over-determined system of inversion equations exists and the analysis has effectively reduced the number of principal components from four to three. Thus, the interpretation of the multivariate nature of the data is simplified and the results can be projected in three-dimensional plots. Only three factors are required to properly conduct a subsequent $R$-mode factor analysis.

Table 2

Results of principal components analysis on original $57 \times 4$ data matrix

\begin{tabular}{lllll}
\hline & PC-1 & PC-2 & PC-3 & PC-4 \\
\hline $\begin{array}{l}\text { Standard } \\
\text { deviation }\end{array}$ & 1.3838 & 1.0944 & 0.7521 & 0.5672 \\
$\begin{array}{l}\text { Proportion of } \\
\text { variance }\end{array}$ & 0.4787 & 0.2994 & 0.1414 & 0.0804 \\
$\begin{array}{l}\text { Cumulative } \\
\text { variance }\end{array}$ & 0.4787 & 0.7782 & 0.9196 & 1.0000 \\
\hline
\end{tabular}



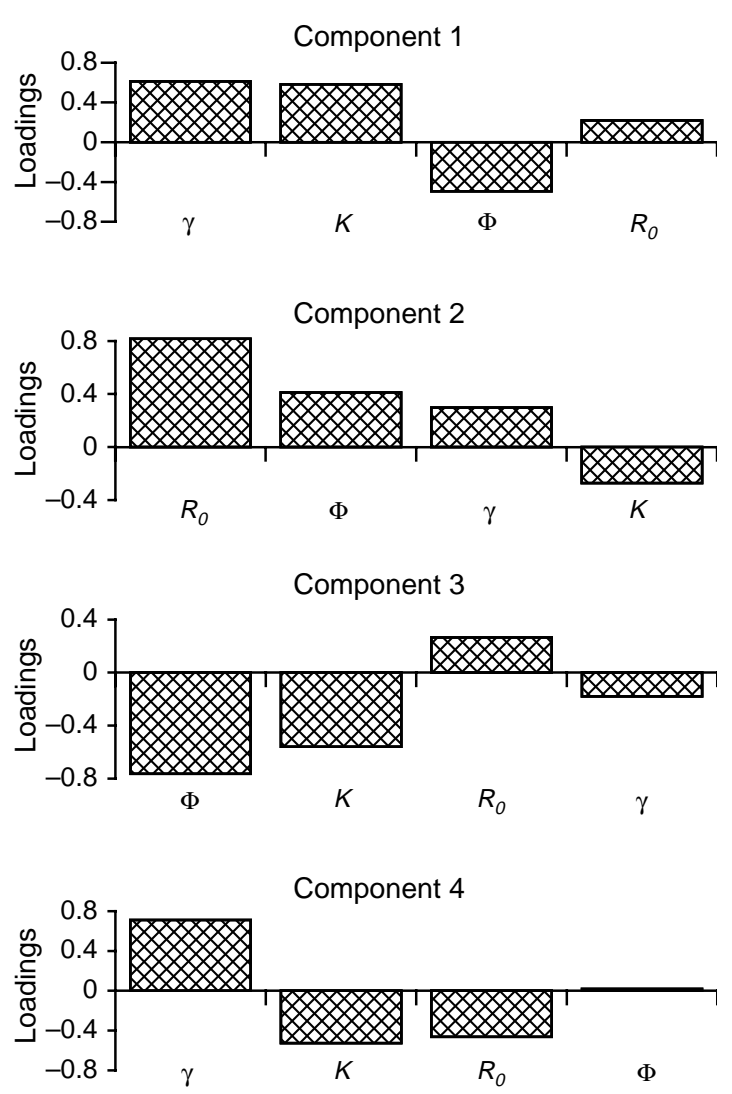

Fig. 6. Principal component loadings associated with individual variables $K$ (hydraulic conductivity), $R_{0}$ (electrical resistivity), $\Phi$ (porosity), and $\gamma$ (natural gamma activity).

A factor analysis was performed in an attempt to reveal any underlying structure or pattern presumed to exist within the multivariate measurements. In this case, an $R$-mode technique was used to investigate the interrelations among variables by determining eigenvalues and eigenvectors from the covariance matrix. In addition, the factors were rotated using a varimax criterion in order to optimize the fit to the original data set. Varimax rotation adjusts the loadings so that the original variables have either a high positive or a high negative correlation with each factor (Davis, 1986). This technique determines the final loadings on the three factors associated with the individual parameters and these are presented in Fig. 7 as a three-dimensional plot of directional vectors corresponding to the axes of Factors 1, 2 and 3.

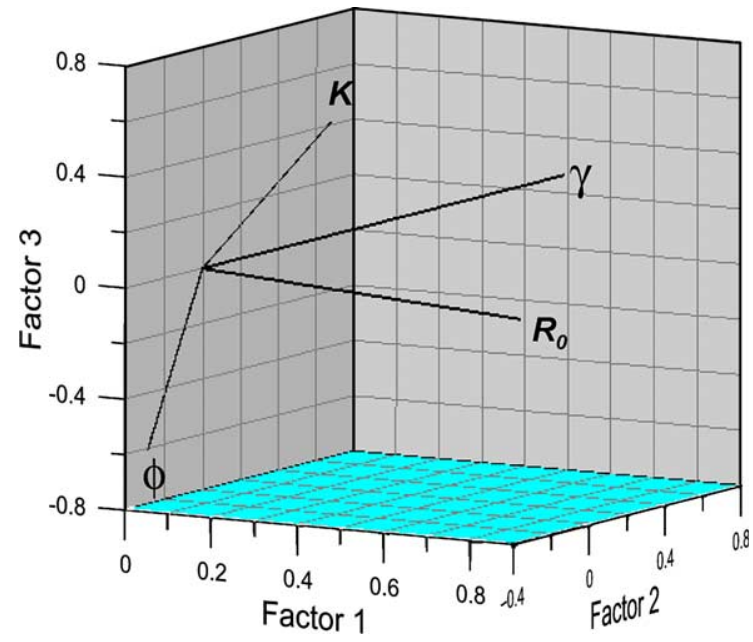

Fig. 7. Plot of loadings on three factor planes rotated by the varimax scheme showing trends among variables.

\subsection{Results and discussion}

The results depicted in Fig. 7 reveal the statistically determined interrelations among the four variables measured in this aquifer. This three-dimensional diagram is presented as a series of two-dimensional faces in Fig. 8 to better examine these interrelations. For the three planes shown in Fig. 8 (Factors 1-2 face; Factors 2-3 face; Factors 1-3 face), the porosity and the hydraulic conductivity are strongly bipolar as they consistently project in opposite directions. Other secondary relations are apparent from these diagrams; one of these implies some degree of interdependence between gamma activity and hydraulic conductivity. A positive $K-\gamma$ correlation is evident in the loadings of Principal Component 1, as shown in Fig. 6, and this principal component accounts for almost half of the cumulative variance (Table 2). The $K-\gamma$ correlation indicates that the presence of coarse, immature glauconitic sands (high gamma counts and large representative grain size) is associated with higher values of hydraulic conductivity. However, the dominant result that emerges from these vector diagrams is the clear negative correlation between the porosity and the hydraulic conductivity. 

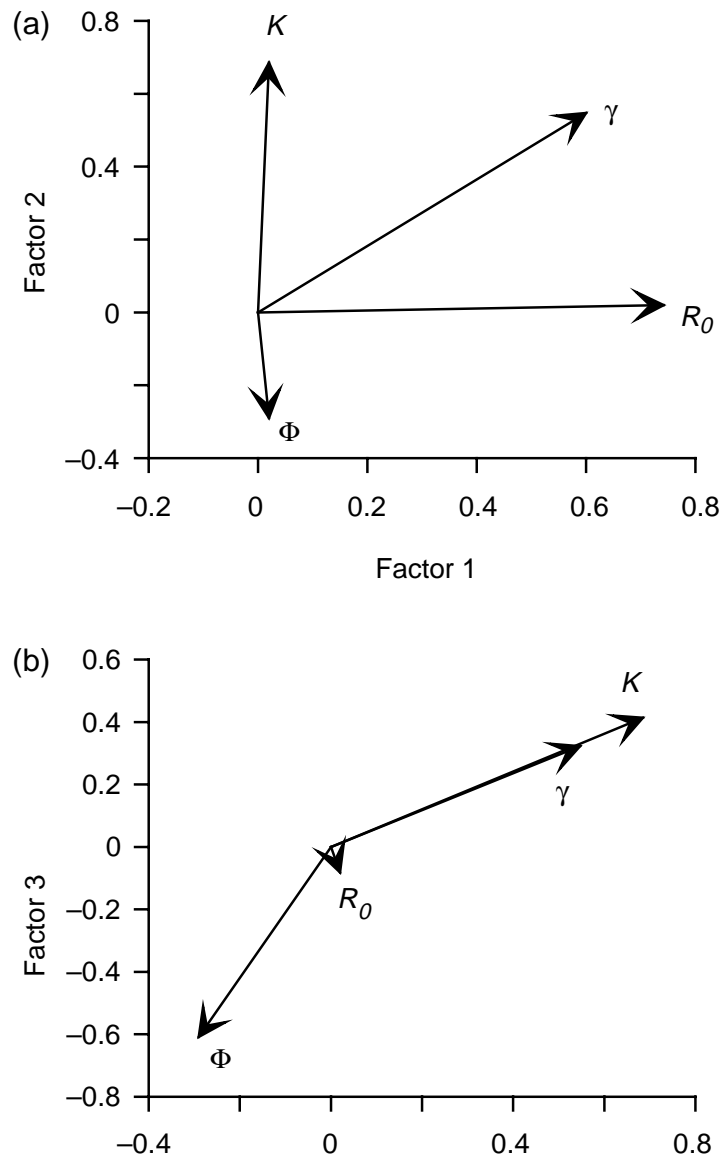

Factor 2

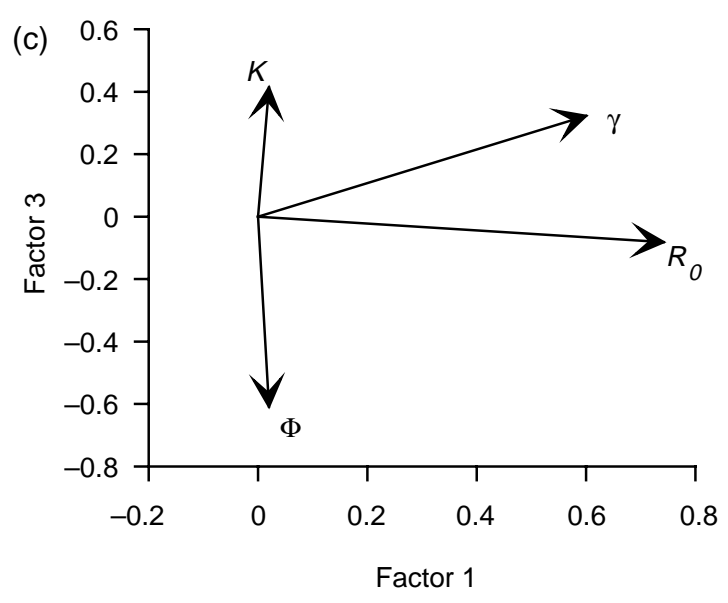

Fig. 8. Two-dimensional diagrams of directional vectors representing loadings on individual variables projected against the three faces shown in Fig. 7.

\section{Summary and discussion}

A trend of decreasing porosity with decreasing effective grain size that reverses as the percentage of fines exceeds some threshold was elucidated by Fraser (1935) from experiments with grain-packing schemes. This reversal depicts a porosity that can increase with decreasing grain size. Other empirical studies (e.g. Hazen, 1911; Pryor, 1973) have demonstrated that hydraulic conductivity is proportional to the square of some representative grain size (Eq. (3)) and systematically decreases as the coarse-grained percentage decreases. Combining the results of these experiments with reports derived from field measurements (e.g. Beard and Weyl, 1973) indicates that it is reasonable to have a granular material with a hydraulic conductivity and a porosity that are negatively correlated under certain grain-size distributions and packing arrangements.

This appears to be the case for the unconsolidated deposits investigated at two sites on Cape Cod. At the Provincetown site, a negative $K-\Phi$ relation was implied from a qualitative analysis of geophysical well logs and this was substantiated at the Falmouth site by a more rigorous multivariate analysis of log data made possible by favorable field-testing conditions. At the latter site, a principal components analysis identified an over-determined system of inversion equations and demonstrated that most of the cumulative proportion of the total variance was accounted for by only three of the four eigenvectors. Accordingly, a three-dimensional factor analysis was applied that depicted the porosity and the hydraulic conductivity as being consistently bipolar, thereby defining a negative $K-\Phi$ relation for these coarse-grained sediments.

The classification of a $K-\Phi$ relation as being either positive or negative relates to the interplay between a fluid winding through a mass of particles at different microscopic velocities, and the shapes and sizes of pores. Additional experimental studies may show this phenomenon to have implications regarding the physical processes associated with groundwater flow and transport through sand-and-gravel aquifers.

\section{Acknowledgements}

The author is grateful to Daniel Urish for providing scientific and logistical support for the Provincetown 
study, and to Denis LeBlanc and Kathryn Hess for their continuing help and hospitality at the Falmouth site. Work at this latter site was partially funded by the USGS Toxic Substances Hydrology Program.

\section{References}

Archie, G.E., 1942. The electrical resistivity $\log$ as an aid in determining some reservoir characteristics. Trans. Am. Inst. Min., Metall. Petrol. Eng. 146, 54-62.

Barber, L.B., Thurman, E.M., Runnells, D.D., 1992. Geochemical heterogeneity in a sand and gravel aquifer: effect of sediment mineralogy and particle size on the sorption of chlorobenzenes. J. Contam. Hydrol. 9, 35-54.

Barrash, W., Morin, R.H., 1997. Recognition of units in coarse, unconsolidated braided-stream deposits from geophysical log data with principal components analysis. J. Geol. 25 (8), 687-690.

Beard, D.C., Weyl, P.K., 1973. Influence of texture on porosity and permeability of unconsolidated sand. Am Assoc. Petrol. Geol. Bull. 57 (2), 349-369.

Biella, G., Lozej, A., Tabacco, I., 1983. Experimental study of some hydrogeophysical properties of unconsolidated porous media. Ground Water 21 (6), 741-751.

Clarke, R.H., 1979. Reservoir properties of conglomerates and conglomeratic sandstones. Am. Assoc. Petrol. Geol. Bull. 63 (5), 799-803.

Davis, J.C., 1986. Statistics and Data Analysis in Geology, 2nd ed. Wiley, New York. 646 pp.

Fraser, H.J., 1935. Experimental study of the porosity and permeability of clastic sediments. J. Geol. 83 (8), 910-1010.

Graton, L.C., Fraser, H.J., 1935. Systematic packing of spheres, with particular relation to porosity and permeability. J. Geol. 43, 785-909.

Hazen, A., 1911. Discussion of 'Dams on sand foundations' by A.C. Koenig. Trans. Am. Soc. Civil Eng. 73, 199.

Hearst, J.R., Nelson, P.H., Paillet, F.L., 2000. Well Logging for Physical Properties, 2nd ed. Wiley, New York. 483 pp.

Hufschmied, P., 1986. Estimation of three-dimensional statistically anisotropic hydraulic conductivity fields by means of single well pumping tests combined with flowmeter measurements. Hydrogeologie 2, 163-174.

Kassenaar, J.D.C., 1991. An application of principal components analysis to borehole geophysical data, Proceedings of the Fourth International Symposium on Borehole Geophysics for Minerals, Geotechnical and Groundwater Applications, Toronto, Ontario pp. 211-218.

Kolterman, C.E., Gorelick, S.M., 1995. Fractional packing model for hydraulic conductivity derived from sediment mixtures. Water Resour. Res. 31 (12), 3283-3297.

Kwader, T., 1985. Estimating aquifer permeability from formation resistivity factors. Ground Water 23 (6), 762-766.

Kwader, T., 1986. The use of geophysical logs for determining formation water quality. Ground Water 24 (1), 11-15.
LeBlanc, D.R., 1984. Sewage plume in a sand and gravel aquifer, Cape Cod, Massachusetts. US Geological Survey Water Supply Paper 2218. 28 pp.

LeBlanc, D.R., Guswa, J.H., Frimpter, M.H., Londquist, C.J., 1986. Ground-water resources of Cape Cod, Massachusetts. US Geological Survey Hydrologic-Investigations Atlas HA-692, 4 plates.

Marion, D., Nur, A., Yin, H., Han, D., 1992. Compressional velocity and porosity in sand-clay mixtures. Geophysics 57 (4), 554-563.

Morin, R.H., Urish, D.W., 1995. Hydrostratigraphic characterization of a coastal aquifer by geophysical log analysis. Cape Cod National Seashore, Massachusetts. The Log Analyst 4, 27-37.

Morin, R.H., LeBlanc, D.R., Teasdale, W.E., 1988a. A statistical evaluation of formation disturbance produced by well-casing installation methods. Ground Water 26 (2), 207-217.

Morin, R.H., Hess, A.E., Paillet, F.L., 1988b. Determining the distribution of hydraulic conductivity in a fractured limestone aquifer by simultaneous injection and geophysical logging. Ground Water 26 (5), 587-595.

Nelson, P.H., 1994. Permeability-porosity relationships in sedimentary rocks. The Log Analyst 3, 38-62.

Oldale, R.N., 1981. Pleistocene stratigraphy of Nantucket, Martha's Vineyard, the Elizabeth Islands, and Cape Cod, Massachusetts. In: Larson, G.J., Stone, B.D. (Eds.), Late Wisconsinan Glaciation of New England. Kendall-Hunt, Dubuque, Iowa, pp. 1-34.

Oldale, R.N., 1992. Cape Cod and The Islands, The Geologic Story. Parnassus Imprints, East Orleans, MA, 208 pp.

Pryor, W.A., 1973. Permeability-porosity patterns and variations in some Holocene sand bodies. Am. Assoc. Petrol. Geol. Bull. 57 (1), 162-189.

Rehfeldt, K.R., Hufschmied, P., Gelhar, L.W., Schaefer, M.E., 1989. Measuring hydraulic conductivity with the borehole flowmeter. EPRI Topical Report EN-6511, Electric Power Research Institute, Palo Alto, CA.

Shepherd, R.G., 1989. Correlations of permeability and grain size. Ground Water 27 (5), 633-639.

Strahler, A.N., 1972. The environmental impact of ground water use on Cape Cod. Report of the Assc. for the Preservation of Cape Cod, Orleans, MA, Impact Study no. 3, 68 pp.

Uchupi, E., Giese, G.S., Aubrey, D.G., Kim, D.J., 1996. The late quaternary construction of Cape Cod, Massachusetts: A reconsideration of the W.M. Davis model. GSA Special Paper 309. Geological Society of America, Boulder, CO, 69 pp.

Urish, D.W., O’Reilly, M.J., Wright, R.M., Frohlich, R.K., 1993. Assessment of ground and surface water impacts: Provincetown landfill and septic disposal site, Provincetown, Massachusetts. National Park Service Technical Report NPS/NARURI/NRTR92/01, 23 pp.

Vukovic, M., Soro, A., 1992. Determination of Hydraulic Conductivity of Porous Media From Grain-size Composition. Water Resources Publications, Littleton, CO. 83 pp.

Zeigler, J.M., Tuttle, S.D., Tasha, H.J., Ciese, G.S., 1965. The age and development of the Provincelands Hook, Outer Cape Cod, Massachusetts. Limnology and Oceanography 10, 298-311. 